\title{
Particulate Matter Produced by Micro-Scale Biomass Combustion in an Oxygen-Lean Atmosphere
}

\author{
Jan Poláčik ${ }^{1}$, Ladislav Šnajdárek ${ }^{1}$, Michal Špiláček ${ }^{2, *}$, Jiři Pospíšil ${ }^{1}$ [D and Tomáš Sitek ${ }^{1}$ \\ 1 Energy Institute, NETME Centre, Brno University of Technology, Technická 2896/2, \\ 61669 Brno, Czech Republic; jan.polacik@vutbr.cz (J.P.); snajdarek@fme.vutbr.cz (L.Š.); \\ pospisil.j@fme.vutbr.cz (J.P.); tomas.sitek@vutbr.cz (T.S.) \\ 2 Sustainable Process Integration Laboratory-SPIL, NETME Centre, Brno University of Technology, \\ Technická 2896/2, 61669 Brno, Czech Republic \\ * Correspondence: michal.spilacek@vutbr.cz; Tel.: +420-541-142-573
}

Received: 30 October 2018; Accepted: 21 November 2018; Published: 1 December 2018

\begin{abstract}
This article extends earlier research by the authors that was devoted to the experimental evaluation of ultra-fine particles produced by the laboratory combustion of beechwood samples. These particles can have severe influence on human health. The current paper presents a parametrical study carried out to assess the influence of the composition of the atmosphere and the temperature on the production of ultra-fine particles during the micro-scale combustion process. The paper presents a laboratory procedure that incorporate the thermogravimetric analysis (TGA) and detailed monitoring of the size distribution of the produced fine particles. The study utilises the laboratory scale identification of the formation and growth of the fine particles during the temperature increase of beech wood samples. It also compares the particle emissions produced by beech heartwood and beech bark. The size of the emitted particles is very strongly influenced by the concentration of light volatiles released from the heated wood sample. From the experimental study, decreasing oxygen content in the atmosphere generally results in higher particulate matter (PM) production.
\end{abstract}

Keywords: particulate matter; fine particles; combustion particles; nucleation; particle growth

\section{Introduction}

In recent years, the monitoring of air pollution has been heavily focused on particulate matter (PM) [1,2]. The negative impact of fine and ultra-fine particles has been studied by many authors. Ultra-fine particles are dangerous to human health [3] and have much greater active surface than larger particles with comparable weight and, therefore, have a greater ability to bind to other harmful substances [4]. Particles smaller than 1 micrometre $\left(\mathrm{PM}_{1}\right)$ are less than the minimum size for the lung's self-cleaning ability. The smallest particles can even diffuse through the wall of alveolar sacs and into the bloodstream [3]. The ultra-fine particles are produced during combustion processes due to a rise in temperature. Internal combustion engines and small furnaces are the main producers of ultra-fine particles in urban areas [5] and most of the particles produced by these combustion processes are $\mathrm{PM}_{1}$ [6], which becomes increasingly problematic in urban areas with a high density of residents using cars and small furnaces. The production of ultra-fine particles from these sources is significant and the final emission concentrations are dependent on the conditions of dispersion. Unfortunately, city buildings are a great obstacle for air flow at the canopy layer of air and the low air velocity creates conditions for a long residence time of particulates in air [7]. Ultra-fine particles do not sediment and can remain in the environment for days and weeks. They are separated from the air by touching a solid surface like walls, roads, vegetation, or a liquid surface like water bodies or raindrops. The ultra-fine particles can grow to fine particles by (i) coagulation mechanisms, that aggregates colloidal and 
macromolecular organic particles into larger clusters, (ii) by agglomeration, where particles bonding is based on the adhesion of the surfaces, by (iii) oxidation reactions or by (iv) condensation of condensable vapours on the particle surface [8].

This paper focuses on the emissions of ultra-fine particles released by the combustion process occurring in a small biomass furnace. There is a vast variety of those furnaces and in each of them are different combusting conditions. Some parts of the furnaces have intense air flow that causes the flying of ash. Sides of a combustion chamber are intensively heated by exothermic reactions as there is a high concentration of volatiles in the combustion chamber. These volatiles undergo incomplete combustion due to a lack of intake air and then cool down and condense - a mechanism resulting in the nucleation of ultra-fine particles.

The measurement of the ultra-fine particles dispersed in the flue gas is important for identifying the effects of furnace operating parameters (heat power output, a surplus of combustion air, temperature) on the resulting emissions of the particles. Such measurements are also used for comparison of different fuels in one furnace [9], but these experimental measurements do not provide detailed insight at the sub-stages of the process of nucleation and subsequent agglomeration of particles. Numerous studies published by different authors deal with this topic, but the process of particle nucleation is still not sufficiently explained and clarified [10-12]. It is necessary to continue with the experimental investigation of numerous samples and analyse the result for a better understanding of the nucleation and the growth process. These processes are studied in laboratory conditions with ideal combustion of fuel samples. This experimental research is the main target of this paper and uses thermogravimetric analysis (TGA) for the identification of particles emitted from a small sample of wood. The measuring instrument provides the particle size distribution of particulate matter. It is very important to understand the nucleation and creation of these particles in the combustion process to create viable strategies for their elimination.

An earlier study by the authors [13] dealt with a laboratory investigation of fine particulate matter production from the controlled heating of beechwood samples in the atmosphere with $21 \%$ oxygen. This paper extends this previous experimental investigation by using lower oxygen content in the atmosphere during laboratory combustion. The limiting test case uses an inert atmosphere with $100 \%$ nitrogen.

\section{Particulate Formation}

When heat flux is applied to the solid phase of woods it is divided into three distinctive layers: (i) the char layer, (ii) the pyrolysis layer and (iii) raw wood. Between the char and pyrolysis layer is identified the char front in which occurs transition from raw wood into char by thermal decomposition (pyrolysis). This transition is usually considered to take place at the $300{ }^{\circ} \mathrm{C}$ isotherm, called the char-line [14].

When external heat flux affects the wood surface, part of the heat is reflected from the surface. Convective heat transfer between surrounding gases and the wood surface also occurs. In the pyrolysis layer, water evaporation occurs first and is later accompanied by pyrolysis reactions and the production of gas volatiles. Vapour and gas volatiles penetrate through pores and leave the wood.

Released volatile components have different values of partial pressure. When they reach their respective saturation point, the formation of a new phase begins - this is the nucleation process. The molecules are clustered into ultra-fine particles up to $0.1 \mu \mathrm{m}$ in size. These particles can further grow by mechanisms mentioned in the introduction section. Particles that are formed in the combustion chamber are called primary particles. Particles formed in the flue gas duct and in the atmosphere are called secondary particles. Organic particles have different levels of volatility that divides them into volatile organic compounds (VOC) and semi-volatile organic compounds (SVOC) [15]. 


\subsection{Soot}

Soot is a spherical particle of impure carbon coated in polyaromatic hydrocarbons (PAHs) [16]. These pollutants are usually the result of a fuel-rich combustion at high temperatures (over $900{ }^{\circ} \mathrm{C}$ ). Combustion at low temperatures (under $700{ }^{\circ} \mathrm{C}$ ) results in $\mathrm{CO}, \mathrm{VOC}$, smoke species, and soot coated in oxidized PAHs [17]. Production of soot can also occur in fuel-lean conditions if some parts of the fuel cannot be accessed by the combustion air both in the fuel bed and in the freeboard flue gas.

Modelling of soot formation is based on experimental work on laminar flames of simple and clean fuels like ethylene and methylene, and to date, no model describes the formation precisely. But there is an agreement on the basic mechanism of soot formation, and a mechanism known as HACA - hydrogen abstraction- $\mathrm{C}_{2} \mathrm{H}_{2}$ addition, that also describes the evolution of PAHs, manages to describe the nucleation of soot [18]. For the description of this mechanism, a basic chemical and physical frame was created. In the chemical frame, the main precursor of soot formation is considered to be acetylene $\mathrm{C}_{2} \mathrm{H}_{2}$ that is reacting to create higher hydrocarbons (aromatics with one or two rings) that are the basis of PAH [19]. Once the PAH is formed, the physical frame can be used to describe the rest of the formation. This consists of four steps: formation (nucleation), coagulation, condensation, and surface growth [19]. Coagulation and condensation are shown in Figure 1. These two steps are creating agglomerates that, after further reactions, turn into impure carbon nuclei. Oxidation by $\mathrm{O}_{2}$ and $\mathrm{OH}$ appears at all steps [18]. The main source of these pollutants is incomplete combustion and is controllable to some degree, because when biomass is combusted on grate pyrolysis always takes place, by the quality of the combustion process.

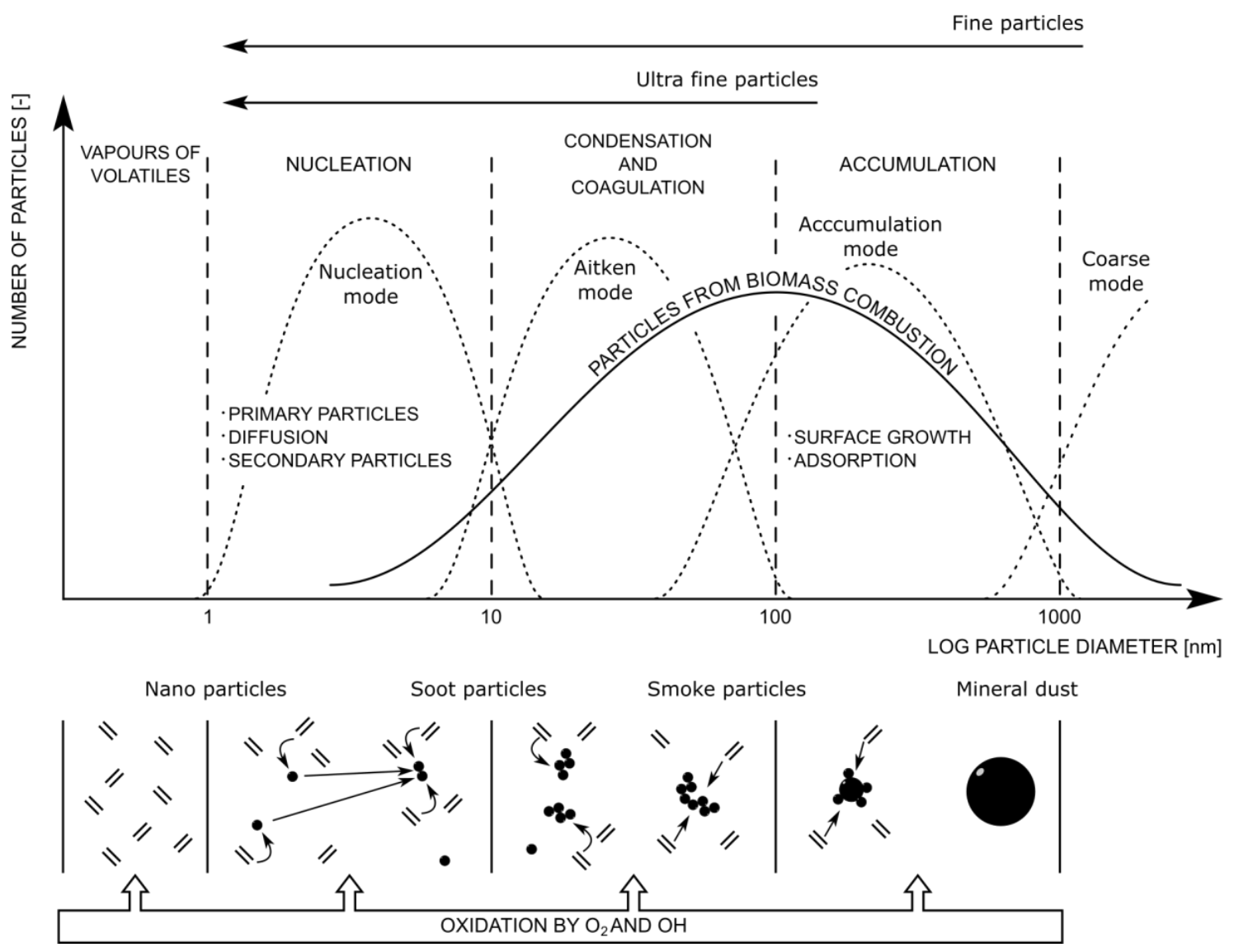

Figure 1. Nucleation and growth of combustion particles. 


\subsection{Fly Ash}

Biomass generally contains trace amounts of metals and the most important of them is potassium [17]. These metal elements are released during combustion and create the compounds responsible for fouling the equipment after condensing on its walls. But some of these compounds leave the combustion equipment in the form of aerosols that are dangerous for human health by themselves or when they create particles of fly ash in a similar fashion to the formation of soot particles. The reason for this is that these mechanisms are interconnected.

The inception and growth of ultra-fine particles are very complex processes in which it is difficult to quantify the intensity of individual incremental changes. A certain help in the quantification is numerical modelling, but despite the great advances in the development of models and the greater computational resources, it is not yet possible to account for every process and create an exact model of the particulate's inception and growth. Additionally, models of biomass combustion do not usually account for particulates [20].

\section{Experimental Procedure and Measurement Device}

From the previously stated reasons, the focus of this paper is on the laboratory measurements of the size distribution of ultra-fine particles emitted from the combustion of beech wood. The developed laboratory procedure incorporates the advantages of thermogravimetric analysis and the detailed monitoring of the size distribution of the produced fine particles. Thermogravimetric analysis (TGA) allows to monitor the exact influence temperature has on a small fuel sample according to the desired heating schedule by monitoring the weight of the heat affected sample and identifying the weight loss. TGA can also change the composition of the atmosphere flowing around the sample. By analysing the development of temperature change, it further identifies the presence of endothermic and exothermic reactions.

The measurement was carried out by utilising a STA 449 F3 Jupiter TGA device (NETZSCH, Selb, Germany). The base component of the STA-449 analyser is a very precise digital weighing system with a vertical design. The analysed samples are placed into a shielded ceramic module (TG-module). This module is linked to the weighting system itself. For the whole duration of the measurement, the entire module is located in a gas-tight laboratory furnace with a controlled heating rate. For each measurement the device provides a TGA curve showing the relationship between weight change and the temperature of the sample.

The gas phase volatiles released by pyrolysis from the fuel sample during the measurement are scattered in the test atmosphere and removed from the device. Subsequently, the resulting stream is cooled down to the ambient temperature by flowing through the connected pipeline, creating an aerosol stream that enters a Scanning Mobility Particle Sizer (SMPS). In SMPS are separated fractions of different particle size. The production of fine particles during the process of combustion of the wood sample was measured with a TSI-SMPS device (Model 3080-Series Electrostatic Classifiers including CPC 3775, TSI Inc., Minneapolis, MN, USA). The SMPS consists of an aerosol neutralizer and differential mobility analyser (DMA).

Almost every particle has some level of electric charge. The DMA requires the aerosol to achieve a uniform and steady charge distribution. This is achieved with an aerosol neutralizer device, which provides a process that neutralises the charge of particles. After neutralisation, the particles pass through a bipolar charger and are all charged to a unified level. Then, the aerosol flows into the DMA where sizing occurs, see Figure 2. 


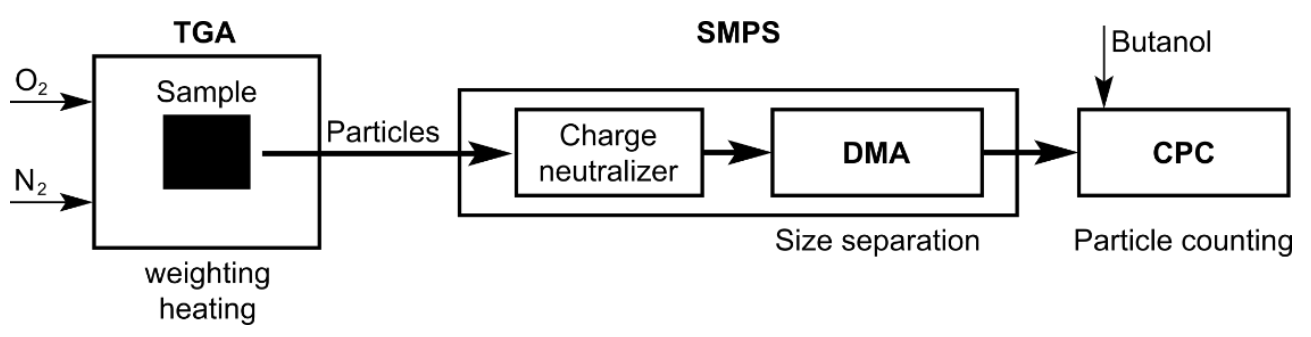

Figure 2. Scheme of the measuring equipment and the particles' flow.

As a particle sizing system, the DMA separates particles by size for high-resolution measurements of the particle size distribution and allows particles in the range of 10 to 1000 nanometers in diameter to be classified. The size of the particles in the polydisperse aerosol flowing though the DMA is determined by their electrical mobility and as only particles of specific sizes are selected, a highly monodisperse aerosol leaves the DMA. This aerosol continues to a condensation particle counter (CPC). The purpose of this device is to measure the particle number concentration and identify particles in the particle-size fractions.

The CPC function is based on condensation of butanol vapours on the monodisperse aerosol's particles that act as condensation nuclei. The condensation occurs in a cooled condenser and the particles grow into larger droplets of such size that they can be counted by an optical detector when passing through it [9].

\section{Experimental Results and Discussion}

Many parameters vary during the combustion process. Temperature and combustion air surplus being the most variable depending on the location in the combustion chamber. The measuring apparatus described in the previous section was used for the research of nucleation and growth of the fine particles in the flue gas from beechwood combustion.

Plants and trees are mainly composed by cellulose fibrils [21]. Next to the cellulose cell walls of wood are composed by lignin and hemicellulose. Cellulose and hemicellulose together are called holocellulose. These three together principally represents the total carbohydrate fraction and are considered as the bulk of wood. The proportions of holocellulose and lignin are different in various parts of woody plants, and, therefore, their residues (sawdust, bark) have different compositions. The beech is a genus of trees and the beechwood have the following composition: extractables $(2 \%)$, lignin (20\%) and holocellulose (78\%) [22], as shown in the Table 1.

Table 1. Chemical composition of beechwood. Adapted with permission from Elsevier [22].

\begin{tabular}{cc}
\hline Description & Value \\
\hline Density & $730 \mathrm{~kg} / \mathrm{m}^{3}$ \\
Humidity & $6.1 \%$ \\
Lignin & $20 \%$ \\
Holocellulose & $78 \%$ \\
$\alpha$-cellulose & $50 \%$ \\
Extractives & $2 \%$ \\
\hline
\end{tabular}

Blocks of beechwood were used as testing samples with each block weighing $80 \mathrm{mg}$. The samples were heated up in the thermogravimetric analyser from $20^{\circ} \mathrm{C}$ to $620^{\circ} \mathrm{C}$ over a period of $120 \mathrm{~min}$. The constant temperature increase was set at $+5^{\circ} \mathrm{C} / \mathrm{min}$. The experiments were carried out for beech heartwood and beech bark. To simulate the wide spectrum of possible conditions of the combustion process the samples were heated up in atmospheres with different oxygen concentrations, namely with the concentrations of $0 \%, 5 \%, 10 \%$ and $15 \%$ of oxygen. Each atmosphere was prepared by mixing pure oxygen and pure nitrogen from pressurised vessels connected to the TGA device. 
Mass loss occurs during the controlled heating up the samples as shown in Figure 3. This figure presents the temperature pattern of wood samples (increasing curve) and the associated weight loss of the samples (decreasing curves). Water evaporates from the tested samples during the temperature increase up to $120{ }^{\circ} \mathrm{C}$, then light volatile compounds are released in the interval from $120{ }^{\circ} \mathrm{C}$ to $250{ }^{\circ} \mathrm{C}$. In the interval from $250{ }^{\circ} \mathrm{C}$ to $300{ }^{\circ} \mathrm{C}$ occurs a rapid loss of a sample's weight induced by the intensive release of remaining volatile compounds. The release of these volatile compounds is intensified by the heat generated from exothermic reactions that commence within these temperatures. The interval from $300{ }^{\circ} \mathrm{C}$ to $500{ }^{\circ} \mathrm{C}$ is associated with the gradual decomposition of carbon in charcoal. The relations presented at the Figure 3 show the different intensity of incineration of samples in different atmospheres. Higher concentration of the oxygen causes more intensive combustion of charcoal. In the atmosphere formed only by pure nitrogen, $30 \%$ of the sample remained unburned in form of charcoal. Influence of the oxygen content in the atmosphere is similar for beech heartwood and beech bark.

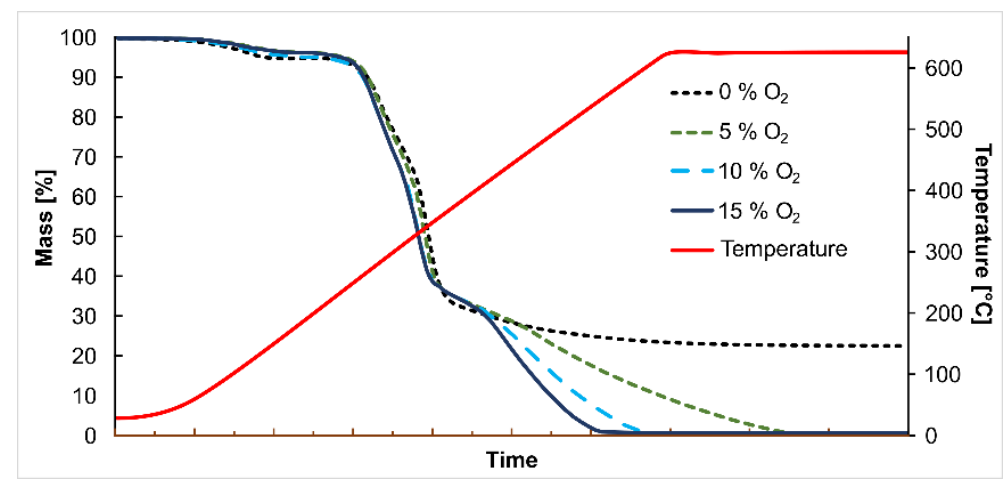

(a)

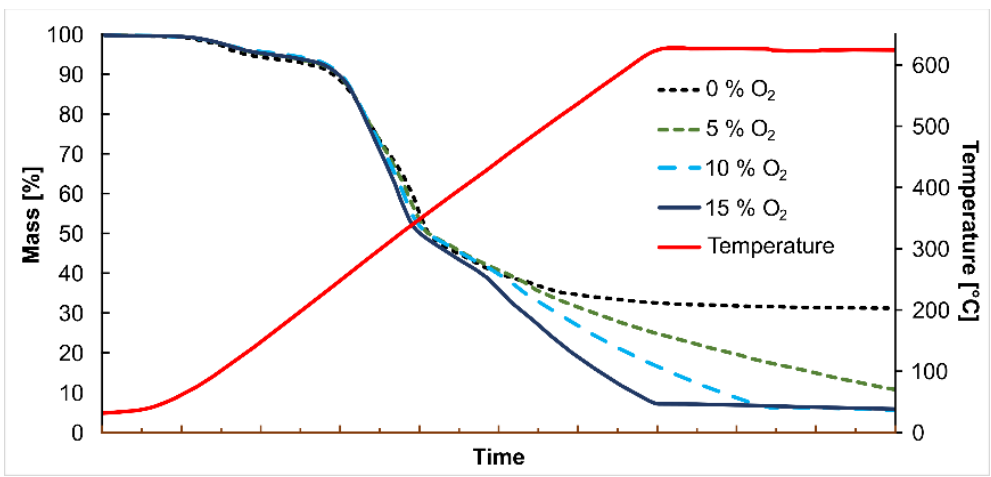

(b)

Figure 3. Results from the thermogravimetric analysis of beech samples in different atmospheres.

(a) Beech heartwood; (b) Beech bark.

The thermal decomposition of the beechwood samples is influenced by the intensity of the oxidation reactions. The result of the thermal decomposition is the production of ultra-fine particles scattered in the gaseous products that leave the TGA apparatus. Figure 4. presents the obtained distribution of the generated particle concentration for all tested concentrations of oxygen in the atmosphere. The presented results represent the sum of all particles generated during the increase of temperature from $20^{\circ} \mathrm{C}$ to $620^{\circ} \mathrm{C}$ over the testing period of $120 \mathrm{~min}$. Significant concentrations of the ultra-fine particles occurred within the particle mobility diameter of $50 \mathrm{~nm}-340 \mathrm{~nm}$ and the maximum concentration corresponds to a particle size around $140 \mathrm{~nm}$. This corresponds to the typical concentration peak of combustion particles formed by the coagulation process. At $300{ }^{\circ} \mathrm{C}$, the highest concentrations of emitted particles were measured. This temperature is close to the ignition 
temperature of the samples and causes an intense production of volatile compounds that subsequently lead to the nucleation of a great number of particles that in turn, coagulate into large particles.

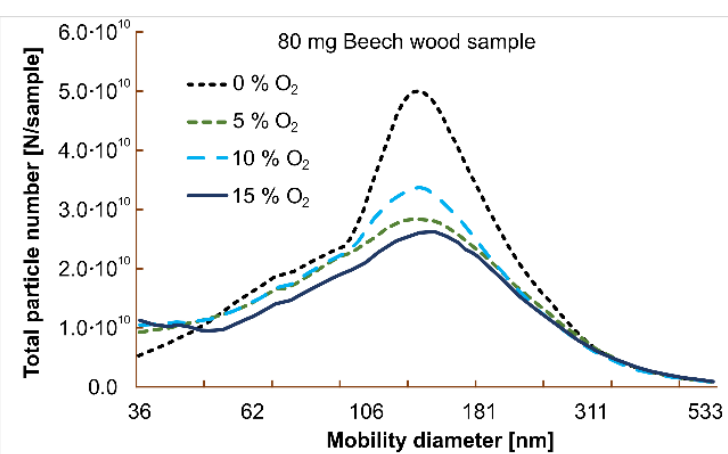

(a)

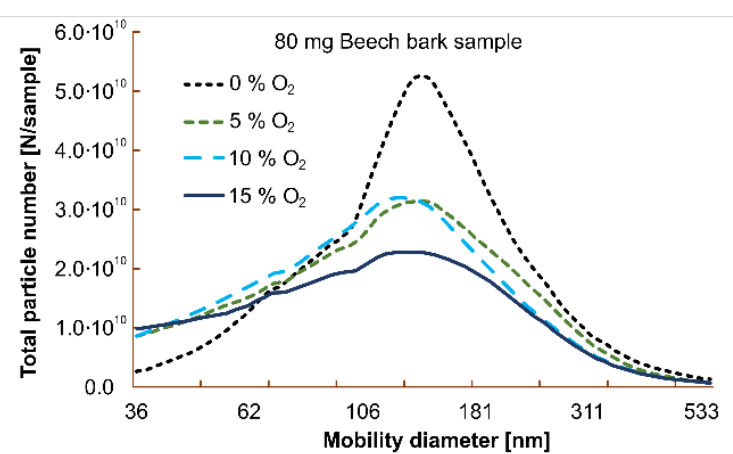

(b)

Figure 4. The distribution curves of the total particle number generated over the testing period. (a) Beech heartwood; (b) Beech bark.

Low concentrations of oxygen in the atmosphere generally caused a higher number of produced particles. This relationship is valid for particle size bigger than $50 \mathrm{~nm}$. In the case of a pure nitrogen atmosphere, significant concentrations of particulate matter were obtained. This is due to the absence of most oxidation reactions, also leading to a decrease in the local temperature affecting other reactions. The dependence of the production of fine parts on the oxygen concentration in the atmosphere is more pronounced when burning beech bark compared to the beech heartwood. Beech bark produces a higher number of particles in the atmosphere of pure nitrogen. The same sample produces a lower particle number in the atmosphere with $15 \%$ oxygen and more.

Figure 5 shows the total mass of all particles generated during the increase of temperature from $20^{\circ} \mathrm{C}$ to $620^{\circ} \mathrm{C}$ over the testing period of $120 \mathrm{~min}$. The maximum total particle mass was identified for particle sizes close to $200 \mathrm{~nm}$. As oxygen concentration in the atmosphere increases, the total particle mass generally decreases. Threshold oxygen concentrations in the atmosphere were identified to be between $5 \%$ and $10 \%$ of oxygen. For oxygen concentrations up to $5 \%$, the higher total particle mass was achieved by burning beech bark; however, for oxygen concentrations of $10 \%$ and above, the higher total particle mass was achieved by burning beech heartwood.

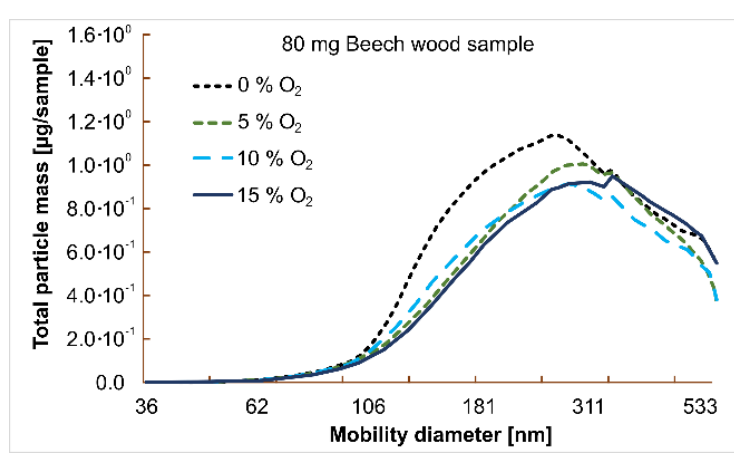

(a)

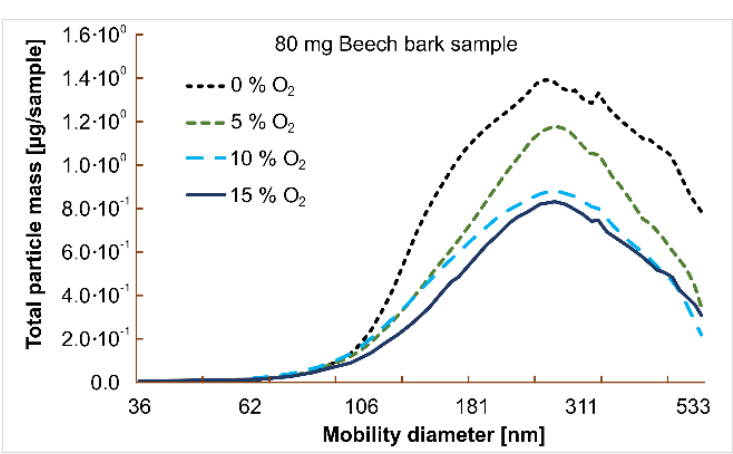

(b)

Figure 5. The relationship between the total particle mass generated over the testing period and the mobility diameter of the particles. (a) Beech heartwood; (b) Beech bark. 


\section{Conclusions}

The fine and ultra-fine particles produced by combustion processes represent a significant health risk. The entire process of inception and growth of these particles is very complex and still not sufficiently described. The study of this issue in actual combustion devices is very difficult due to the instability and diversity of the combustion process due to the wide ranges of devices and fuels. The research presented in this paper focused on the emission of ultra-fine particles from the controlled heating of small samples of beechwood (heartwood and bark). A connection between thermogravimetric analysis and the mobility diameter measurement of particulates was realised for this purpose. Other studies looking into the topic of particulate emissions from biomass combustion were interested in: (i) the chemical composition of released volatile compounds from which particulate matter can form [23-25], (ii) mass amount of particulate matter released by different types of biomass [23,26-28] and (iii) number of released particles [23,26,28]. These studies were conducted on small (domestic) biomass burners for different types of wood (beech included) and under various conditions specified by $\%$ of the nominal output of the device under observation. But wider range of atmospheric conditions is required for modern approaches for biomass combustion [29], pyrolysis $\left(0 \% \mathrm{O}_{2}\right)$ included. The study carried out in this paper was a parametric sweep tracking the influence of different concentrations of oxygen in the atmosphere on the production of particulates during a controlled heat up.

From the experimental measurements it can be concluded that increasing the temperature leads to a higher emission of particles produced by the combustion process. This applies until the ignition temperature is reached. This is most likely due to the increasing concentration of volatile vapours. Just before the ignition temperature the highest amount of volatile vapours is evaporating from the sample leading to the most intensive nucleation of particles resulting in their high concentrations, coagulation and growth. When the ignition temperature of the volatile vapours is reached, which can only happen if oxygen is present, the concentration of these vapours diminishes and so does the production of the particulates. This diminishing process occurs until the maximum experimental temperature of $620^{\circ} \mathrm{C}$.

The utilisation of the thermogravimetric analysis is suitable for the experimental measurement of particulates produced by combustion and is a suitable tool for detailed insight into the sub-processes of the particulate's inception and growth during the combustion process, which can be further expanded by performing the same study for other types of woods. With the information from [30] about the effective density of the particulate matter a deeper insight into the researched problem can be obtained.

Author Contributions: Conceptualization, J.P. (Jan Poláčik) and J.P. (Jiří Pospíšil); Data curation, J.P. (Jan Poláčik) and T.S. (Tomáš Sitek); Methodology, L.Š. (Ladislav Šnajdárek); Supervision, J.P. (Jiří Pospíšil); Visualization, M.Š.; Writing—original draft, M.Š. and J.P. (Jiří Pospíšil).

Funding: This paper has been supported by the EU projects: Sustainable Process Integration Laboratory - SPIL funded as project No. CZ.02.1.01/0.0/0.0/15_003/0000456 and Computer Simulations for Effective Low-Emission Energy funded as project No. CZ.02.1.01/0.0/0.0/16_026/0008392 by Czech Republic Operational Programme Research, Development and Education, Priority 1: Strengthening capacity for high-quality research and the collaboration.

Conflicts of Interest: The authors declare no conflict of interest.

\section{References}

1. Chen, D.; Liu, X.; Han, J.; Jiang, M.; Xu, Y.; Xu, M. Measurements of particulate matter concentration by the light scattering method: Optimization of the detection angle. Fuel Process. Technol. 2018, 179, $124-134$. [CrossRef]

2. Carminati, M.; Ferrari, G.; Sampietro, M. Emerging miniaturized technologies for airborne particulate matter pervasive monitoring. Measurement 2017, 101, 250-256. [CrossRef] 
3. Santibáñez-Andrade, M.; Quezada-Maldonado, E.M.; Osornio-Vargas, Á.; Sánchez-Pérez, Y.; García-Cuellar, C.M. Air pollution and genomic instability: The role of particulate matter in lung carcinogenesis. Environ. Pollut. 2017, 229, 412-422. [CrossRef] [PubMed]

4. Baldock, J.A.; Smernik, R.J. Chemical composition and bioavailability of thermally altered Pinus resinosa (Red pine) wood. Org. Geochem. 2002, 33, 1093-1109. [CrossRef]

5. Karagulian, F.; Belis, C.A.; Dora, C.F.C.; Prüss-Ustün, A.M.; Bonjour, S.; Adair-Rohani, H.; Amann, M. Contributions to cities' ambient particulate matter (PM): A systematic review of local source contributions at global level. Atmos. Environ. 2015, 120, 475-483. [CrossRef]

6. Cheng, Y.; Zou, S.C.; Lee, S.C.; Chow, J.C.; Ho, K.F.; Watson, J.G.; Han, Y.M.; Zhang, R.J.; Zhang, F.; Yau, P.S.; et al. Characteristics and source apportionment of PM1 emissions at a roadside station. J. Hazard. Mater. 2011, 195, 82-91. [CrossRef] [PubMed]

7. Kukkonen, J.; Karl, M.; Keuken, M.P.; Denier van der Gon, H.A.C.; Denby, B.R.; Singh, V.; Douros, J.; Manders, A.; Samaras, Z.; Moussiopoulos, N.; et al. Modelling the dispersion of particle numbers in five European cities. Geosci. Model Dev. 2016, 9, 451-478. [CrossRef]

8. Obaidullah, M.; Bram, S.; De Ruyck, J.; Verma, V.K. A Review on Particle Emissions from Small Scale Biomass Combustion. Int. J. Renew. Energy Res. 2012, 2, 147-159.

9. Kantová, N.; Nosek, R.; Holubčík, M.; Jandačka, J. The Formation of Particulate Matter during the Combustion of Different Fuels and Air Temperatures. Renew. Energy Sources Eng. Technol. Innov. 2018, 47-52. [CrossRef]

10. Kwiatkowski, K.; Zuk, P.J.; Dudyński, M.; Bajer, K. Pyrolysis and gasification of single biomass particle-New openFoam solver. J. Phys. Conf. Ser. 2014, 530. [CrossRef]

11. Lupascu, A.; Easter, R.; Zaveri, R.; Shrivastava, M.; Pekour, M.; Tomlinson, J.; Yang, Q.; Matsui, H.; Hodzic, A.; Zhang, Q.; et al. Modeling particle nucleation and growth over northern California during the 2010 CARES campaign. Atmos. Chem. Phys. 2015, 15, 12283-12313. [CrossRef]

12. Appel, J.; Bockhorn, H.; Frenklach, M. Kinetic modeling of soot formation with detailed chemistry and physics: Laminar premixed flames of C2 hydrocarbons. Combust. Flame 2000, 121, 122-136. [CrossRef]

13. Poláčik, J.; Pospíšil, J.; Šnajdárek, L.; Sitek, T. Influence of temperature on the production and size distribution of fine particles released from beech wood samples. Matec Web Conf. 2018, 168, 1-9. [CrossRef]

14. Cachim, P.B.; Franssen, J.M. Comparison between the charring rate model and the conductive model of Eurocode 5. Fire Mater. 2009, 33, 129-143. [CrossRef]

15. Sippula, O. Fine Particle Formation and Emissions in Biomass Combustion Title. Ph.D. Thesis, University of Eastern Finland, Kuopio City, Finland, 2010.

16. Battin-Leclerc, F.; Simmie, J.M.; Blurock, E. Cleaner Combustion: Developing Detailed Chemical Kinetic Models, 1st ed.; Springer: New York, NY, USA, 2013; ISBN 978-1-4471-6909-3.

17. Williams, A.; Jones, J.M.; Ma, L.; Pourkashanian, M. Pollutants from the combustion of solid biomass fuels. Prog. Energy Combust. Sci. 2012, 38, 113-137. [CrossRef]

18. Desgroux, P.; Faccinetto, A.; Mercier, X.; Mouton, T.; Aubagnac Karkar, D.; El Bakali, A. Comparative study of the soot formation process in a "nucleation" and a "sooting" low pressure premixed methane flame. Combust. Flame 2017, 184, 153-166. [CrossRef]

19. Saini, R.; De, A. Assessment of soot formation models in lifted ethylene/air turbulent diffusion flame. Therm. Sci. Eng. Prog. 2017, 3, 49-61. [CrossRef]

20. Abricka, M.; Barmina, I.; Valdmanis, R.; Zake, M.; Kalis, H. Experimental and Numerical Studies on Integrated Gasification and Combustion of Biomass. Chem. Eng. Trans. 2016, 50, 127-132. [CrossRef]

21. Poletto, M.; Pistor, V.; Zatera, J.A. Structural Characteristics and Thermal Properties of Native Cellulose. In Cellulose-Fundamental Aspects; IntechOpen Limited: London, UK, 2013; pp. 45-68, ISBN 978-953-51-1183-2.

22. Di Blasi, C.; Branca, C.; Santoro, A.; Gonzalez Hernandez, E. Pyrolytic behavior and products of some wood varieties. Combust. Flame 2001, 124, 165-177. [CrossRef]

23. Weimer, S.; Alfarra, M.R.; Schreiber, D.; Mohr, M.; Prévôt, A.S.H.; Baltensperger, U. Organic aerosol mass spectral signatures from wood-burning emissions: Influence of burning conditions and wood type. J. Geophys. Res. 2008, 113. [CrossRef] 
24. Hilbers, T.J.; Wang, Z.; Pecha, B.; Westerhof, R.J.M.; Kersten, S.R.A.; Pelaez-Samaniego, M.R.; Garcia-Perez, M. Cellulose-Lignin interactions during slow and fast pyrolysis. J. Anal. Appl. Pyrolysis 2015, 114, 197-207. [CrossRef]

25. Quan, C.; Gao, N.; Song, Q. Pyrolysis of biomass components in a TGA and a fixed-bed reactor: Thermochemical behaviors, kinetics, and product characterization. J. Anal. Appl. Pyrolysis 2016, 121, 84-92. [CrossRef]

26. Johansson, L.S.; Tullin, C.; Leckner, B.; Sjövall, P. Particle emissions from biomass combustion in small combustors. Biomass Bioenergy 2003, 25, 435-446. [CrossRef]

27. Zosima, A.T.; Ochsenkühn-Petropoulou, M. Characterization of the Particulate Matter and Carbonaceous Particles Produced by Biomass Combustion. Anal. Lett. 2015, 49, 1102-1113. [CrossRef]

28. Torvela, T.; Tissari, J.; Sippula, O.; Kaivosoja, T.; Leskinen, J.; Virén, A.; Lähde, A.; Jokiniemi, J. Effect of wood combustion conditions on the morphology of freshly emitted fine particles. Atmos. Environ. 2014, 87, 65-76. [CrossRef]

29. Rodilla, I.; Contreras, M.L.; Bahillo, A. Thermogravimetric and mass spectrometric (TG-MS) analysis of sub-bituminous coal-energy crops blends in $\mathrm{N}_{2}$, air and $\mathrm{CO}_{2} / \mathrm{O}_{2}$ atmospheres. Fuel 2018, 215, 506-514. [CrossRef]

30. Zhai, J.; Lu, X.; Li, L.; Zhang, Q.; Zhang, C.; Chen, H.; Yang, X.; Chen, J. Size-resolved chemical composition, effective density, and optical properties of biomass burning particles. Atmos. Chem. Phys. 2017, 17, 7481-7493. [CrossRef]

(C) 2018 by the authors. Licensee MDPI, Basel, Switzerland. This article is an open access article distributed under the terms and conditions of the Creative Commons Attribution (CC BY) license (http:/ / creativecommons.org/licenses/by/4.0/). 